\title{
Les terres cuites architecturales dans l'Yonne: prospections thématiques, première campagne
}

\section{Sylvain Aumard}

\section{(2) OpenEdition \\ 1 Journals}

Édition électronique

URL : https://journals.openedition.org/cem/901

DOI : 10.4000/cem.901

ISSN : 1954-3093

\section{Éditeur}

Centre d'études médiévales Saint-Germain d'Auxerre

\section{Édition imprimée}

Date de publication : 15 août 2004

ISSN : 1623-5770

\section{Référence électronique}

Sylvain Aumard, "Les terres cuites architecturales dans I'Yonne : prospections thématiques, première campagne », Bulletin du centre d'études médiévales d'Auxerre | BUCEMA [En ligne], 8 | 2004, mis en ligne le 13 décembre 2006, consulté le 22 septembre 2022. URL : http://journals.openedition.org/cem/901 ; DOI : https://doi.org/10.4000/cem.901

Ce document a été généré automatiquement le 22 septembre 2022.

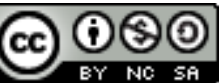

Creative Commons - Attribution - Pas d'Utilisation Commerciale - Partage dans les Mêmes Conditions 4.0 International - CC BY-NC-SA 4.0

https://creativecommons.org/licenses/by-nc-sa/4.0/ 


\title{
Les terres cuites architecturales dans l'Yonne : prospections thématiques, première campagne
}

\author{
Sylvain Aumard
}

1 Cette première année avait pour objectif de mettre en place des outils de recensement (fiches d'objets et d'ateliers) et de procéder à une reconnaissance du potentiel documentaire icaunais. Un rapport de fin d'année a réuni les fiches établies, ainsi qu'un certain nombre de contributions faisant le point sur les principales avancées des chercheurs locaux (carreaux, tuiles, faïences architecturales, productions du XIX siècle, documentation écrite médiévale ou moderne). Cette campagne ${ }^{1}$ a permis de prendre conscience du considérable potentiel de recherche, tant sur les objets manufacturés que sur les ateliers de fabrication. Le survol du potentiel géologique montre, à l'instar de la bibliographie, que le sénonais possède les ressources en argile les plus nombreuses, les plus accessibles et, vraisemblablement celles de meilleure qualité. Ce constat est aussi recoupé par une première tentative de cartographie de l'état actuel des connaissances sur les tuileries médiévales et modernes, essentiellement concentrées dans le nord de l'Yonne ${ }^{2}$. Il est rapidement apparu que les recherches sur les objets manufacturés dépendent pour beaucoup des découvertes fortuites et des opportunités d'observation. À l'inverse, le recensement des ateliers est apparu plus facile à maîtriser par des recherches en archives.

2 Des analyses physico-chimiques sur les carreaux médiévaux de Cudot et des Écharlis ont permis de confirmer la similitude des pâtes en regard de la similitude des motifs incisés. Des études archéomagnétiques ont aussi été réalisées sur des tuiles de la cathédrale de Sens et de l'église de Noyers-sur-Serein. Dans le premier cas, il s'agit de confirmer l'origine médiévale des exceptionnelles tuiles bicolores; dans le second cas, il s'agit de mieux situer la chronologie des petites tuiles plates traditionnelles sur un monument à la chronologie relativement bien établie.

3 La campagne 2004 sera essentiellement consacrée au recensement des tuileries. Ce dernier prendra un caractère systématique dans une bande longeant l'Yonne, de 
Vermenton à Joigny. La poursuite des analyses physico-chimiques et pétrographiques sur les carreaux de Cudot et des Écharlis, ainsi que sur les tuiles des cathédrales d'Auxerre et Sens, devrait permettre de mieux se représenter les caractères spécifiques des argiles auxerroises et sénonaises.

\section{NOTES}

1.. Participants : S. Aumard (titulaire de l'autorisation), F. Cayot, N. Deflou-Leca, J.-P. Delor, J.-P. Desaive, T.-N. Kinder, A. Leriche, M. Orgeur, C. Pellet. Sur le projet de recherche, voir : Études et Travaux, 7, 2002-2003, p. 139-144.

2.. Sur la trentaine d'ateliers recensés, une quinzaine d'entre eux est de l'époque médiévale.

\section{INDEX}

Mots-clés : TCA (Terres cuites architecturales)

Index géographique : France/Yonne 